\title{
A guerra das narrativas: debates e ilusões em torno do ensino de História*
}

\author{
Christian Laville \\ Universidade Laval, Quebec
}

RESUMO

Em quase todas as partes do mundo, os programas escolares exigem que o ensino da bistória desenvolvanos alunos a autonomia intelectual e o pensamento crítico. Há muito tempo não se vê mais a missão de incutir nas consciências uma narrativa úmica glorificandoa nação ou a comunidade. No entanto, quando o ensino da bistória é questionado nos debates públicos, é sempre com referência a esse tipo de narrativa: embora nãofazendo mais parte dos programas, esse continua sendo o único objeto dos debates. Este artigo dá inúmeros exemplos atuais de tais debates, antes de concluir que são provavelmente vãos e que as pessoas se iludem sobre os efeitos reais da bistória ensinada. Alguns exemplos também são dados a esse respeito.

Palavras-chave: Ensino de História; Política; Narrativa.
AbStraCt

Almost everywbere in the world, official school curricula require that the teaching of bistory develop students' capacity for intellectual autonomy and critical thinking. They don't bear anymore the mission to instil in students' consciousness a single narrative glorifying the nation or the community. Still, whenever the teaching of bistory is called intoquestion in public debates, it is always in reference to thissort of narrative: school curricula do not include it, yet it is the sole point of these debates. The article gives several examples of such debates throughout the world. It then concludes that these are most probably pointless debates as it seems we overestimate the actual effects of history education. Examples of this are also given.

Keywords: History Education; Politics; Narrative. 
Para liquidar os povos, começa-se por lbes tirar a memória. Destroem-se seus livros, sua cultura, sua bistória. E uma outra pessoa lhes escreve outros livros, lhes dá outra cultura el lhes inventa uma outraHistória.

Milan Kundera. OLivro do Riso e do Esquecimento, 1978.

Houve um tempo em que o ensino da bistória nas escolas não era mais do que uma forma de educaçáo cívica. Seu principal objetivo era confirmar a nação no estado em que se encontrava no momento, legitimar sua ordem social e política-e ao mesmo tempo seus dirigentes - e inculcar nos membros da nação-vistos, então, mais como súditos do que como cidadãos participantes-o orgulbo de a ela pertencerem, respeito por ela e dedicação para servi-la. Oaparelho didático desse ensino era simples: uma narração de fatos seletos, momentos fortes, etapas decisivas, grandes personagens, acontecimentos simbólicos e, de vez 126 em quando, alguns mitos gratificantes. Cada peça dessa narrativa tinha sua importância e era cuidadosamente selecionada.

Essa maneira de ensinar a bistória foi se tornando menos necessária à medida que as naçóes for am percebendo que estavam bem assentadas e cessaram de temer por sua própria existência. Nos países ocidentais, ofim da Segunda Guerra Mundial foi o marco de uma etapa importante. Oresultado da guerrafoi percebido como a vitória da democracia, uma democracia cujo princípio não se discutia mais a partir de então, mas que precisava agora funcionar bem, ou seja, com a participação dos cidadãos, como manda o princípio democrático. A idéia de "cidadáo participante" começou a substituir a de "cidadão-súdito". Oensino da bistória náo deixou de ganbar com isso. Ao contrário, viu a função de educaçãopara a cidadania democrática substituir sua funçãoanterior de instrução nacional.

Grosso modo, dali em diante era preciso tornar os jovens capazes de participar democraticamente da sociedade e desenvolverneles as capacidades intelectuais e afetivas necessárias para tal. Os conteúdos fatuais passavam a ser menos determinados de 
antemáa, menos exchusivos, abrindo-se à variedade e ao relativo. Contudo, o mais importante é que, como o desenvolvimento das capacidadesse dá com a prática, a pedagogia da história passava de uma pedagogia centrada no ensino para uma pedagogia centrada nas aprendizagens dos alunos.

Todos os países ocidentais parecem ter percorrido esse caminbo, e também é o que ocorre com muitos outros países espaIhados pelos cinco continentes. Para constatar, basta examinar os programas 'propostos' e o discurso com o qual é apresentado atualmente o ensino da bistória. No entanto, em muitos desses países, quando o ensino da bistória é criticado ou acusado, quando provoca debates, como muitas vezes acontece, náo é porque as pessoas se inquietam com o alcance dos objetivos de formação que lhe são oficialmente atribuídos, mas 'em razão' dos conteúdosfatuais, por se julgar que certos elementos estariam ausentes e que outros estariam sendo ensinados em lugar de coisa melhor, como se o ensino da história continuasse sendo o veículo de uma narração exclusiva que precisa ser assimilada custe oque custar. Vê-se aí o estranbo paradoxo de um ensino destinado a uma determinada função, mas acusado de não cumprir outra que não lhe é mais atribuída. Há numerosos casos assim neste fim de século e alguns deles seráo evocados aqui. Em seguida, e para concluir, consideraremos um outro paradoxo decorrente do primeiro: o de se acreditar que pela manipulação dos conteúdos é possível dirigir as consciências ou as memórias, quando a experiência do presente século mostra que está longe de ser tão certo assim quanto tantos parecem acreditar, oque provavelmente náo passa de uma grande ilusão.

EXEMPLOS ILUSTRATIVOS (1): PARA MANTER A ORDEM ESTABELECIDA

A maioria das vezes, o que está em jogo nos debates a respeito dos conteúdos do ensino da bistória é a manutenção de uma determinada tradição. O caso dos National Standardsfor History nos Estados Unidos é um bom exemplo disso.

Nos Estados Unidos, como se sabe, a educação é da responsabilidade dos Estados e não da administraçãofederal. Há algum tempo, no entanto, o governo federal americano vinba se mos- 
trando inquieto com relação ao ensino da bistória, por duas razóes, entre outras. Primeiro, porque se julgava que os bomens de negócios americanos perdiam muito por conbecerem insuficientemente as culturas estrangeiras; em seguida, porque se acreditava que a bistória facilitaria a integração das minorias culturais.Jána administração do presidente Reagan, um relatório sobre a educação intitulado A Nation at Risk fizera referência à educaçãobistórica; na de Bill Clinton, os governadores dos Estados aprovaram um projeto de reforma da educação, o projeto America $2000^{1}$, que insistia para que a bistória se tornasse matéria básica para todos. No mesmo momento, outros se preocupavam com a erosão dos conbecimentos culturais dosjovens americanos, ou com o espaço crescente ocupado pelo ensino de social studies ao lado das disciplinas tradicionais de história e geografia ${ }^{2}$.

Foi nesse contexto que um grupo de bistoriadores e de pedagogos, juntamente com várias centenas de consultores e de especialistas de todas as partes, elaborou um projeto de normas nacionais para o ensino da bistória, os national standardspara oensi128 no de história dos Estados Unidos e de história geral . Em tais circunstâncias, oque devia ser apenas um conjunto de sugestóes apresentadas aos Estados logose transformou numa querela nacional. A direita se enfureceu. Embora sugerindo certos conteúdos, pois não se pode ensinar bistória sem conteúdos, o que os standards propunham, essencialmente, eram objetivos de formação, mas somente os conteúdos são atacados. Oque se dizé que, com essa abertura à bistória mundial, astaisnormas estariam insuflandoum relativismo cultural e colocando em perigo a civilização ocidental branca e cristã e, conseqüentemente, a civilização americana; ao se abrir à bistória social, aos imigrantes, às mulheres, aosnegros, aotratar do Klu Klux Klan e do McCartysmo, as normas estariam querendo obscurecerheróis como Washington, Thomas Edison ou Paul Revere e deixando apenas um pequeno espaço para a Constituiçãó. Mesmoqueo governofederalnãotenhanada aver com a educação, Newt Gïngrich, líder republicanona Câmara, conseguiu levar a questãoao Senadoe fez com que os senadores se pronunciassem sobre os standards: 99 delesvotaram contra, um se absteve (porque não achava a condenação bastante consistente). 
Pouco tempo antes, um debate semelhante ocorrera na Inglaterra a respeito do ensino da bistória. Na Inglaterra, não bavia um programa nacional para essa disciplina. As escolas e os professores gozavam de uma grande liberdade na definiçáo e na prática do ensino. Eles haviam, contudo, elaborado um programa, o Schools Council History Project, que terminara sendo adotado por aproximadamente um terço dos professores e exercia uma grande influência sobre o ensino de bistória em geral. Era um programa moderno, que seguia a tendência dos programas atuais descritos na introdução, mas ensinado com essa grande liberdade desfrutada pelos professores britânicos e, portanto, com muita variedade nos conteúdos. O governo conservador da época, e a própria Margaret Thatcher, preocuparam-se com isso. Podia acontecer, e efetivamente acontecia, que se ensinasse pouco a respeito da Inglaterra e de seu passado glorioso, por exemplo, nos enclaves de comunidades culturais onde se procurava tornar a bistória facilmente acessível aos alunos, com assuntos próximos da realidade deles, em detrimento, segundo os conservadores, da aquisição de uma memória comum bem britânica.

Foi iniciada, então, a preparação de exames nacionais, seguida de um programa nacional de história, o National Curriculum for History, com os conteúdos desejados pelos conservadores, é claro. Aqui, mais uma vez, o debate em torno dos conteúdos, tanto na mídia quanto na opiniáo pública, foi intenso e durou vários anos ${ }^{6}$. Mas o debate também foi intenso entre os professores, muitos dos quais resistiram e acabaram conseguindo um acordo que passou a vigorar desde o início do ano letivo de 1995, acordo esse que preserva em parte os objetivos de formação que eles queriam conservar, embora com abundantes conteúdos prédeterminados.

Muitos outros exemplos ilustrativos poderiam ser citados. Lembremo-nos de um outro debate vigoroso que agitou a França na década de 1970 e no início da década de 1980, quando da implantação de uma reforma dos programas de bistória, a qual, pela primeira vez, rompia com a tradição dos programas iniciada na Terceira República. Centrados no aluno, orientados para o desenvolvimento das capacidades e privilegiando uma pedago- 
gia de aprendizagem pela descoberta, e náo uma pedagogia da recepção, os novos programas pareciam negligenciaralgunspersonagens nacionais da cronologia tradicional. Houve indignaçãoem todas as famílias políticas, ao ponto de se ver surgir aquela estranba coligaçãoformada pelo gaullista Michel Debré, pelo socialista Jean-Pierre Chevenement e pelo bistoriador popular Alain Decaux, coligação essa que foi batizada pelosjornalistas de "Santa Aliança da História Nacional”. Dois presidentes, sucessivamente, vieram juntar-se ao cortejo de indignados: Valéry Giscard-d'Estaing e, depois, François Mitterrand, que declarou estar "escandalizado e angustiado com as carências do ensino da bistória". A reforma não resistiu durante muito tempo e, a partir de meados da década de 1980, voltava-se ao que havia de mais convencional.

É interessante notar quanto interesse, quanta vigilância e quantas intervençóes o ensino de bistória suscita nos mais altos níveis. Abistória é certamente a única disciplina escolar que recebe intervençóes diretas dos altos dirigentes e a consideração ativa dos parlamentos. Isso mostra quáo importante é ela para opoder.

EXEMPLOS ILUSTRATIVOS (2): QUANDO OS ESTADOS SE RECONSTITUEM

Entre as decisóes tomadas pelos vencedores aofim da Segunda Guerra Mundial, bouve a de proibir o ensino da bistória ministrado nos países vencidos, a fim de neutralizar seus conteúdos fatuais antes de substitui-los por outros. Foi uma das primeiras decisóes, senáo a primeira, do Alto Comando aliado em Berlim; a mesma coisa se deu na Itália e noJapão.

Cinqü̈enta anos mais tarde, apesar do avanço efetuado pelo ensino de bistória, ainda é assim que o tratam quando se passa de um regime a outro. Os ex-países do leste europeu oferecem inúmeros exemplos disso.

Na maioria deles, mal a transição começou, o ensino de bistória já era submetido à revisão: revisão dos programas e dos manuais, e sobretudo dos manuais, mais do que da pedagogia, pois tudo isso é principalmente uma questão de narrativa. Grosso modo, essa revisáo consiste em reescrever, apagando aquilo que se quer esquecer do antigo regime e introduzindo ou reintroduzindo-as famosas "páginas brancas"-o que parece necessário 
para a construção ou consolidação da memória coletiva que se queragora.

Às vezes, o realinhamento é brutal. Foi assim na ex-Alemanba Oriental . De um dia para o outro, ou quase, osmanuaisforam retirados e os professores de bistória foram suspensos: porque estudaram e ensinaram "a história errada", e não se via como poderiam, agora, ensinar a "certa". É claro que isso provocou reaçóes. Ossindicatos se envolveram, os meios de comunicação, entre os quais os estrangeiros, abordaram o assunto. Decidiu-se, então, que osprofessores seriam, eventualmente, recontratados, mas somente depois de passarem porum exame, baseado essencialmente no pensamento liberal. Exames do mesmo tipoforam empregados noutros lugares. Àsvezes, havia até questóes sobre a Bíblia.

Ainda na Alemanba Oriental, como os manuais náopodiam ser refeitos de um dia para o outro, começaram a ser importados manuais da Alemanba Ocidental. Assim, na Saxônia, um dosländer mais avançados econômica e culturalmente, o ano letivo de 1991 foi iniciado com manuais de bistória da Baviera, onde a corrente conservadora é muito importante.

Mesmo não sendo sempre tão brutal, a mudança é geralmente brusca. Na Rússia, por exemplo, mal a glasnost bavia começadoe já se julgava que os instrumentos usados no ensino da bistória deviam ser substituídos. E como eles não podiam ser substituídos instantaneamente, foram suspensos os exames oficiais e, em muitas escolas, o próprio ensino de bistória. Na Ucrânia, desdeo início da liberalização, houve trêsfases de transição: do totalitarismoà democracia, da economia dirigida ao livre mercado, de república dependente a Estado independente. Conforme a socióloga Irina Bekesbkina, cada uma dessasfasesfoi acompanbada por uma nova interpretação histórica, cada uma delas amparada por um novo discurso político. Assim, segundo ela, o capitalismo, que era definido como "um sistema de exploração moribundo", tornou-se "um futuro brilhante"; a nação, antigamente "destinada a desaparecer no processo de reunião da comunidade soviética", tornou-se a base fundamental da vida bumana e da bistória ${ }^{9}$...

Na pressa, cada comunidade quer seu manual, sua narrativa bistórica própria. Quando não é possível prepará-lo com bastan- 
te rapidez, usam-se velbos livros, totalmente ultrapassados do ponto de vista historiográfico. Assim, para os quatro milhóes de lituanos, foi novamente publicada, com uma tiragem de 155.000 exemplares, uma bistória da Lituânia que data da década de $1930^{10}$. Aconteceu a mesma coisa na República Tcheca, onde, após os acontecimentos de 1989, os editores colocaram de novo no mercado os manuais de bistória do Estado tcheco e tchecoslovaco publicados entre 1918 e 1938 ou entre 1945 e 194811. Em outros lugares, acontece de simplesmente traduzirem osmanuais de bistória estrangeiros, como na Rússia, onde existe atualmente oprojeto de tradução de um manual americano de bistória geral que, a meu ver, os jovens russos vão achar bem estranbo!

Cada comunidade quer ver a sua própria bistória contada. Na Rússia, mais uma vez, um colega me disse estar ligado ao projeto de elaboração do manual de uma pequena comunidade do Norte, composta de 50.000 babitantes, aproximadamente, que patrocina, com a ajuda de um imposto especial, a redação de sua bistória singular. Na Bósnia, cada comunidade também deseja tanto tero 132 seu próprio ensino de bistória que são redigidos manuais diferentes, com narrativas e beróis diferentes-às vezes adversários-para osjovens sérvios, croatas ou muçulmanos. Até pensaram em adotarprogramas de bistória diferentes numa mesma escola.

Nessas bistórias, encontram-se freqüentemente os antigos defeitos das historiografias nacionalistas escolares que pensávamosjá terem desaparecido: legitimação, justificação, glorificação, mitificação, mobilização das consciências, às vezes com a inteira submissão do ensino da história à causa de um nacionalismo exaltado. Assim, na Estônia, os próprios autores da reforma do ensino de bistória explicam: "Toda a reforma do ensino da bistória devia ser, antes de tudo, uma lut a para resgatar e reforçar a identidade nacional. Toda a bistória estomiana foi reorganizada, no novo programa reformulado, seguindo uma linba nacionalista. Atrama bistórica foi sobreposta ao projeto nacional"12. Também foi assim na Eslovênia, onde Vesna Gidiva e Valentina Hlebec constatam que: "É mais do que evidente que ensinar história é antes de tudo um trabalbo ideológico e político e não uma questão de normas profissionais"13. 
Se os ex-países do leste europeu oferecem bons exemplos da maneira como a bistória é tratada quando um Estado é reconstituído, não é só nesses países, evidentemente, que ocorrem tais situaçóes. Pensemos na África do Sul, por exemplo, onde foi só após um debate muito longo e árduo - a narrativa de uma bistória negra? branca? com que densidade relativa de branco e de negro?-que o Ministério da Educação acabou elaborando seu projeto para a redação de novos manuais e conseguiu fazer com que o Parlamento o aprovasse (mas o debate corre o risco de continuar, pois os novos manuais só são esperados para o ano 2000). Pensemos igualmente na China, onde, três meses antes da reanexação de Hong Kong, o ministro dos Assuntos Exterioresjá estava anunciando, diante da Assembléia Nacional Popular, que os manuais seriam revistos, pois, explicava ele, "o conteúdo de certos livros escolares atualmente usados em Hong Kong não está conforme à História e à realidade. Eles não são compativeis com as mudanças que vão ocorrer em 1997 e são contrários ao espírito do princípio 'um paús, dois sistemas', bem como à Constituição"'í. Como se dizia em Moscou, o passado é imprevisível! É verdade que a China ainda não tem a obrigação de implantar um ensino da história que prepare para a participação democrática.

EXEMPLOS ILUSTRATIVOS (3): PARA LUTAR CONTRA O ESTADO

Àsvezes, sãogrupos dissidentes que atacam as narrativas bistóricas impostas ao ensino pelo Estado. NoJapão, por exemplo, bá várias décadas historiadores e professores, apoiados pordiversos grupos, entre os quais uma associação para a verdade na bistória composta de milhares de membros, combatem a censura que o Ministério da Educação exerce sobre o conteúdo dos manuais. É uma censura muito rigorosa. Tudo o que, aos olbos do ministério, poderia diminuir a imagem positiva doJapão na bistória é proibido. Para contar os fatos, é preciso utilizar um vocabulário padronizado. Assim, para falar da invasáo da China peloJapão na década de 1930, deve-se falar de "progressão militar"; para falar da pilbagem de Nankin em 1937, quando 150.000 civis foram massacrados, conta-se que "o exércitojaponês ocupou a cidade num ambiente de agitação excessiva e de cólera”; é preciso escre- 
ver "incidente" ao invés de "revolta", "suicídio coletivo de civis" ao invés de "massacre", "mulheres de conforto" ao invés de "prostitutas" De manifestação em manifestação, de processo em processo - alguns dos quais chegaram até à corte suprema -, bem como sob as pressóes estrangeiras, a situação parece estar se amenizando um pouco. De fato, não é mais necessário falar da anexação da Coréia em 1910 como sendo uma "fusão pacífica", e o Primeiro Ministro aceitou reconbecer, bá algum tempo, a questão das "esposas de consolação"'s . Nesse ensino da bistória, porém, são sempre e unicamente os termos da narrativa que estão em causa.

No México, em 1992, é uma coalizão de liberais e de progressistas que ataca os manuais de história para o primário que o governo de Carlos Salinas queria impor. No contexto das negociaçóes do mercado comum norte-americano, os novos manuais elogiavam as políticas econômicas presentes e passadas do México e sua abertura ao capitalismo internacional, ao mesmo tempoque minimizavam os episódios contestatórios ou revolucionários de suabistória. Odebate foi enérgico e os manuaisforam revistos ${ }^{16}$.

134 Anarrativa bistórica pode também ser vista como uma tomada de poder por grupos sem poder. Vejamos um exemplo disso no Brasil, onde, em vários Estados, principalmente em Minas Gerais e São Paulo, os professores de bistória haviam lutado, durante a ditadura, para conseguir um programa cujo conteúdofosse definido de acordo com seu ponto de vista de militantes. No caso de Minas Gerais, eles queriam opor aos programas oficiais, de cunbo nacionalista e positivista, um conteúdo de bistória marxista clássico que apresentasse as etapas sucessivas de formação econômica e integrasse o nacional ao universal. Tratava-se, sobretudo, de trocar uma narrativa por outra narrativa. Esse programa foi conseguido com a redemocratização, mas, agora, como ocombate, em grande parte, esgotou-se, parece que os professores fazem menos questão de afirmarem seu poder ${ }^{17}$.

EXEMPLOS ILUSTRATIVOS (4): DEFINIR UMA IDENTIDADE SUPRANACIONAL

Todosos exemplosanteriores de fixaçãoem relação ànarrativa bistórica è̀sua manipulaçãoocorriamnoâmbitodanação. Maspode ocorrerque se queira ofereceruma narrativa situada além dessecon- 
texto e que até reduza o seu alcance. É o caso do projeto de ISESCO deproporaos alunos dospaísesmuçulmanos um programa islâmico de ensino da bistória. Trata-se de ensinar, aos ahnos dos diferentes paúses, que, apesarde suas identidadesnacionais, elespentencemantes de tudo à grande comunidade dos muçulmanos. Os seguintes trechos dos objetivos do projeto dáo testemunbo disso: "enraizaroaluno em sua identidade individual e nacional, fixando-o na commidade muçulmana e destacando ofato de que sua identidade oliga intimamente, por meio de laços indeléveis, religiosos, bistóricos e culturais, à comunidade islâmica”; “desenvolverno ahno o senso da responsabilidade e osentimento de orgullho em relação à comunidade islâmica, com base na força desta e na convicção da necessidade de instaurar a unidade muçulmana em todos os setores"; "o que procuramos destacar, através dos assuntos escollhidos para esse programa, é que os povos muçulmanos formaram, ao longo da bistória, uma única comunidade ligada por laços de cooperação e de complementaridade"18. Enfim, oprograma consiste numa longuíssima lista das matérias a serem ensinadas, matérias querepresentam as balizas detaIhadas de uma outra narrativa feita sobmedida para daruma roupagemàúmica identidadeabmejada.

Atualmente, entre os indígenas das Américas, também está surgindo uma vontade similar de ter uma narrativa bistórica que se situe deliberadamente acima dos Estados. Assim, a última parte do programa nacional de bistória do Quebec e do Canadá adotado pelos índios Cris trata, ironicamente, do advento da "pátria cri"'?

Essas são algumas ilustrações daquilo que anunciamos na introdução como um primeiro paradoxo: enquanto na maioria dos países se diz que o objetivo do ensino da bistória é desenvolver nos alunos as capacidades de que o cidadão precisa para participar da sociedade de maneira autônoma e refletida, o ensino da bistória, ainda é, muitas vezes, reduzido a uma narrativa fechada, destinada a moldar as consciências e a ditar as obrigaçóes e os comportamentos para com a nação. Observou-se que, quando, em nosso mundo, bá um debate público em torno do ensino da bistória, é essa narrativa que está quase sempre em jogo. 
Essa observação nos leva a constatar um segundo paradoxo: o de acreditar em semelhante ensino da bistória, quando muitos fatos parecem mostrar que pensar que ainda é possível regular as consciências e os comportamentos por meio do ensino da bistória não passaria de uma vã ilusão. A experiência, de fato, mostra outra coisa. Aqui vão alguns exemplos disso.

Para começar, vejamos oque ocorre em Quebec. Durante mais de meio século, os únicos objetivos do ensino da bistória eram ensinar aos canadenses de língua francesa a necessidade de sobreviver enquanto povo e de proteger a lingua e a fé, além da adesáo ao grande todo canadense, que era a garantia para tal sobrevivência. Assim, lia-se entre os objetivos principais dos programas: "O estudo da bistória de nosso país contribuirá para formar meIhor o bom cidadão do Canadá de amanhã "'o" "fazer desse ensino uma verdadeira lição de educação nacional que desenvolva em todos os nossos alunos o orgulbo legítimo de dizer que sáo cidadãos do Canadá e a ambição de se tornar um perfeito cidadáo e de contribuir para o progresso e para a grandeza do povo canaden-

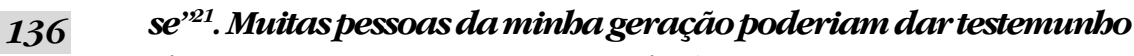
de que os programas eram seguidos à risca. No entanto, na primeira oportunidade, na virada dos anos 1950, os quebequenses fizeram, em alguns meses, exatamente o oposto do que lhes vinha sendo ensinado, dia após dia, bá mais de meio século. E logo a metade deles começou a dizer que queria se separar daquele Canadáque haviam queridoobrigá-losa amar.

Outro exemplo na ex-União Soviética. Durante várias décadas, haviam ensinado ali, por meio da bistória, que o capitalismo era o inferno e que o socialismo abriria as portas do paraíso. $O$ que fizeram os membros das diversas repúblicas assim que tiveram a oportunidade? Escolheram o inferno!

Outro exemplo, desta feita na Alemanba. Uma pesquisa recente mostra que os jovens da Alemanba Ocidental e da Alemanba Oriental, oriundos de sociedades que conbeceram ensinos de bistória bem diferentes, não apresentam, no entanto, diferenças significativas em suas representaçóes, conceitos e atitudes ${ }^{22}$.

Outro exemplo, tirado também da pesquisa que acaba de ser mencionada: na Cisjordânia e na banda de Gaza, onde o exército 
israelita controla o ensino da bistória e censura os manuais, os jovens palestinos desenvolveram uma consciência bistórica sem relação com os conteúdos do ensino da bistória ${ }^{23}$.

Tudo isso para dizer que é possível que todos esses esforços para controlar os conteúdos do ensino da bistória, bem como os debates que isso provoca, estejam alicerçados numa ilusão. Neste fim de século, é possível que a narrativa bistórica não tenba mais tanto poder, que a família, o meio ao qual se pertence, circunstâncias marcantes no ambiente em que se vive, mas sobretudo os meios de comunicação, tenham muito mais influência. $O$ que deveria nos levar a não perder de vista a função social geralmente declarada boje a respeito do ensino da bistória: formar indivíduos autônomos e críticos e levá-los a desenvolver as capacidades intelectuais e afetivas adequadas, fazendo com que trabalhem com conteúdos bistóricos abertos e variados, e não com conteúdos fechados e determinados como ainda são com freqüência as narrativas que provocam disputas. Senão, essas guerras de narrativas desencadeadas em todo o mundo vão acabar gerando somente perdedores, tanto no que diz respeito à identidade naciomal quanto em relaçãoà vida democrática.

\section{Notas}

*Tradução do texto: Francisco Pereira de Lima.

${ }^{1}$ USDE, America 2000: An Education Strategy. Washington, GPO, 1991 (que se tornou lei em 1994 com o título de Goals Educate America Act).

${ }^{2}$ Ver por exemplo: HIRSCH, E. D. Cultural Literacy. What every American needs to know. Nova Iorque, Vintage, 1988; RAVITCH, Diane et FINN, C. E. What do our 17-year-olds know? New York, Harper and Row, 1987; CHENEY, Lynn. American Memory: a Report on the Humanities in the Nation's Public Schools. Washington, NEH, 1987.

${ }^{3}$ National Standards for History for Grade K-4. Expanding Children's World in Time and Space; National Standards for United States History. Exploring the American Experience. Grade 5-12 et National Standards for World History. Exploring Paths to the Present. Grades 5-12. Los Angeles, National Centerfor History in the Schools, 1994.

${ }^{4}$ Para obter mais detalbes sobre essa polêmica, ver NASH, Gary B., CRABTREE, Charlotte e DUNN, Ross E. History on Trial: Culture Wars and the Teaching of the Past. New York, Alfred A. Knopf, 1997. Um resumo desses acontecimentos pode ser encontrado em WINKIER, Allan. "Who chopped down the cherry tree?”. Times Higher Education Supplement, 10 de março de 1995, p.19.

${ }^{5}$ Department of Education. History in the National Curriculum, Londres, HMSO. 
${ }^{6}$ Em "La bataille des programmes. Le débat sur l'enseignement de l'bistoire et la recherche en Allemagne de l'Ouest, en Grande-Bretagne et en Suède”. In Revue d'Allemagne, vol. 25, $n^{\circ}$ 02, 1993, pp. 203-211, Carl-Axel Gemzell compara esse debate com outros semelhantes ocorridos na Alemanba e na Suíça, osquais não serão abordados aqui.

${ }^{7}$ Entre outras obras sobre a polêmica, leia-se Des enfants sans histoire. Enquête de Jean-François Fayard. Paris, Perrin, 1984.

${ }^{8}$ A respeito do ensino de história durante a transição na ex-Alemanba Oriental, ver AHONEN, Sirkka. Clio sans Uniform. A Study of the Post-Marxist Transformation of the History Curricula in East Germany and Estonia, 19861991. Helsinque, Suomalainen Tiedeakatemia, 1992.

${ }^{9}$ In ANGVIK, Magne e BORRIES, Bodo von (eds). Youth and History. A Comparative European Survey on Historical Consciousness and Political Attitudes among Adolescents. Hamburgo, Edition Körber-Stiftung, 1997, vol. A: Description, p. A275 (a traduçãoé nossa).

${ }^{10}$ Trata-se do livro Lietuvos istorija de A. Sapoka, $1^{a}$ ed. 1936. Ver Idem, p. A265.

${ }^{11}$ Segundo CORNEJ, Petr. "Politique, histoire et histoire scolaire". In Revue internationale d'éducation. no 13, março de 1997, p. 90.

${ }^{12}$ ÖISPUU, Silvia. New Tendencies in History Education in Estonia with Retrospect into the Past. Göteborg, Göteborgs Universitet, 1993, p. 10 (a tradução é nossa). Ver também AHONEN, op. cit.

${ }^{13}$ ANGVIK, Dans et BORRIES, von. op. cit., p. A 288 (a tradução é nossa).

14“Hong-Kong: 'un pays, deux systèmes', quelle bistoire?”. In Le Devoir. 11 de marçode 1997.

${ }^{15}$ Ver HORIO, Terubisa. "Éducation et conscience politique". In Revue internationale d'éducation, op. cit., p.107; ver também CONAN, Éric. "Le Japon ne veut pas d'bistoire”. In L'Express. 27 de julbo de 1995, pp. 53-56.

${ }^{16}$ A esse respeito, ver NASH, CRABTREE e DUN. op. cit., p. 133.

${ }^{17}$ Ver, a esse respeito, SIMAN, Lana Mara de Castro. Changement paradigmatique et enjeux sociopolitiques en enseignement de l'bistoire: le cas du programme d'bistoire du Minas Gerais (Brésil) et les réactions paradoxales des enseignants. Tese de Doutorado, Université Laval, 1997.

${ }^{18}$ ISESCO. Projet de programme d'enseignement de l'bistoire islamique et de la géographie. s. l., 1998, p.14, 29.

${ }^{19}$ Commission scolaire crie. Histoire du Québec et du Canada. Programme adapté, junbo de 1994.

${ }^{20}$ Programme d'études des écoles secondaires, 1961. Quebec, p. 200.

${ }^{21}$ Programme d'études des écoles élémentaires, 1959. Quebec, p. 482.

${ }^{22}$ Ver ANGVIK e BORRIES, von. op. cit., p. A 218. Ver também KLOSE, Dagmar. "Bouleversement de la conscience de l'histoire". In Revue internationale d'éducation. op. cit., p. 72.

${ }^{23}$ Idem, p. A322.

Artigo recebido em abr:/99, aprovado em ago./99 